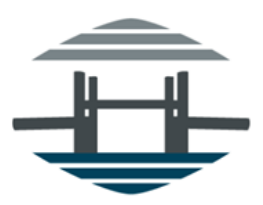

\title{
The effect of very low bearing pressure on the behavior of cast-in anchors
}

\author{
Giuseppe Di Nunzio $^{(1)}$, Angelo Marchisella ${ }^{(2)}$, Giovanni Muciaccia ${ }^{(3)}$ \\ (1) Department of Civil and Environmental Engineering, Politecnico di Milano, Milano, Italy, \\ giuseppe.dinunzio@polimi.it \\ (2) Department of Civil and Environmental Engineering, Politecnico di Milano, Milano, Italy, \\ angelo.marchisella@polimi.it \\ (3) Department of Civil and Environmental Engineering, Politecnico di Milano, Milano, Italy, \\ giovanni.muciaccia@polimi.it
}

\begin{abstract}
The effect of bearing pressure on the behavior of cast-in anchors is addressed presenting the results of an experimental campaign on cast-in anchors with different head type and same embedment depth. In particular, three cast-in anchor solutions were tested with the anchor-head ranging from relatively small head (high bearing pressure) to very large head-size (low bearing pressure). For the small head-size only, the anchor is installed using high strength grouting mortar after the hardening of the base concrete material. The concrete base member was lightly reinforced. Anchors were tested under axial force and different mechanical response (load-displacement) are observed. Failure modes change depending on the anchor's type. The force transfer mechanism might migrate from pure concrete cone formation to structural collapse of the concrete base member. In some cases, the cone surfaces can be clearly recognized despite of the presence of a splitting crack. In other tests a plate failure was obtained, characterized by the presence large triangular segments between cracks radially arranged. This aspect is strictly related to the bearing pressure at the anchor-head location. Indeed, a hydrostatic stress-strain field is developed with different gradients according to the head-size. Small head-size leads to an increasing of the bearing pressure with severe crushing of concrete and consequent reduction of the expected load capacity. Furthermore, the observed failure mechanism suggests that the crack pattern propagation is unaffected by the presence of grouting mortar.
\end{abstract}

Keywords: Cast-in anchor, Concrete Cone Failure, Splitting Failure, Bearing Head Pressure, Head Size.

\section{INTRODUCTION}

\subsection{State of the art}

In the past, the design and the verification of fastening in concrete was limited to simply detailing rules and to the designer's experience. Due to relative recent development of efficient post-installed fasteners, most of research efforts were dedicated to their structural safety and their influence in the global behavior of the structures. The most important results have been included in codes and national regulations, which encompass both the assessment and the design of fastening systems.

As reported by [1], the failure mechanism of anchors in concrete was first described by Seghezzi. Specifically, a hydrostatic pressure condition in the concrete is established in a very small zone around the expansion shell of the anchor. In this region the concrete is severely crushed. A system of circumferential tension cracks runs from the load transfer zone to the surface of the concrete. In addition, radial cracks occur starting at the surface [1]. As anchors employ the local tensile capacity concrete, [2] found that concrete cone failure is affected by size-effect. On this basis, [3] proposed the Concrete Capacity Design (CCD) approach (or CC approach in United States), which is currently adopted in the most recent codes and national regulations.

The expression for the concrete cone capacity of an anchor, sufficiently spaced from other anchors and far from free edges, is given by (1).

$$
N_{u, c}=k_{1} \cdot f_{c c}^{0.5} \cdot h_{e f}^{1.5}
$$




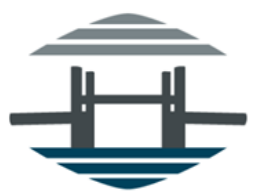

Where: $k_{1}$ is a constant determined by linear regression analysis of the obtained failure loads and it is equal to 15.5 in case of mean value of the capacity, $f_{c c}$ is the compressive strength of concrete measured on cubes and expressed in $\mathrm{N} / \mathrm{mm}^{2}, h_{e f}$ is the effective embedment depth.

EN1992-4 [4] adopts the (1) without any modification, ACI 318, Annex D [5] allows the use of a modified version, which is given by (2). In that modified version, the constant and the leading coefficient for the embedment depth are modified by regression analysis of results from test with large embedment depths.

$$
\begin{gathered}
N_{u, m}=16.8 \cdot f_{c}^{0.5} \cdot h_{e f}^{1.5} \text { for } h_{e f}<280 \mathrm{~mm} \\
N_{u, m}=6.585 \cdot f_{c}^{0.5} \cdot h_{e f}^{5 / 3} \text { for } h_{e f} \geq 280 \mathrm{~mm}
\end{gathered}
$$

The CCD approach is based on the assumption that the capacity is unaffected by the size of the anchor head. Several authors investigated the behavior of cast-in anchors with different head-sizes and large embedment depths. Specifically, they found how the head-size has strong influence on the pull-out capacity for cast-in anchors. Larger head-size yields to lower permanent displacements and to greater load capacities with respect to CCD previsions. For large embedment depths and low bearing pressure, [6] suggest the use of the method given by (3), because the CCD approach could be conservative. That is because the method is based on linear fracture mechanics, which is valid only for anchors with high bearing pressure (i.e. anchors with small heads) [6]. From results of numerical analyses, [7] found how the increasing of the head-size of the anchor leads the size effect on the failure capacity of anchors to decrease; therefore the pullout resistance increases with increase of the head size. Hence, a corrective coefficient for the (1) is proposed. That coefficient is defined as in (3), and it yields to an increasing of the load capacity as function of the bearing area and the embedment depth.

$$
\gamma^{k}=\left(\frac{A_{b}}{A_{b, \text { code }}}\right)^{\frac{\sqrt{h_{e f}}}{100}}
$$

Where: $A_{b}$ is the bearing area, $A_{b, c o d e}$ is an equivalent bearing area, which yields to a bearing pressure equal to $20 \cdot f_{c c}$ while the capacity reaches the value from CCD method.

In a very recent $\mathrm{PhD}$ thesis, [8] proposed a refined concrete cone approach for cast-in anchors, on the basis of experimental and numerical results. That approach defines several modification factors, which take into account the effect of the head-size, the thickness of the member and the surface reinforcement. The proposed coefficient for the head-size effect is defined by (4), where the only difference with (3) is on the threshold for the bearing pressure, which is fixed to $15 \cdot f_{c c}$.

$$
\psi_{A H}=\left(\frac{A_{b}}{A_{b, \text { code }}}\right)^{0.1}
$$

According to the author [8], the CCD method was not developed in consistent way with respect to the size of the anchor heads over the range of the studied anchor embedment depths, because the bearing stresses under the heads of the tested anchors varied significantly.

\subsection{Scope of the work}

The present research project aims to investigate the pullout behavior of cast-in anchor solutions. The most recent theoretical models adopted by national codes worldwide are based on the so-called CCD (or CC in US) approach. Such a calculation method it is believed to be conservative, but it is also rather simplified, and it does not take directly into account for various parameters, among which the size of the anchor head. Within this context, the structural response of cast-in anchors is investigated varying the size of the bearing head keeping fixed the embedment depth. The plane of the paper is as follow: in the section titled "Materials and methods" details of the experimental setup are reported; in the section titled "Test results" the outcome of the experimental campaign are described; in the section titled "Discussion of results" the results are linked with available analytical models; finally, some conclusions place this work in a larger context. 


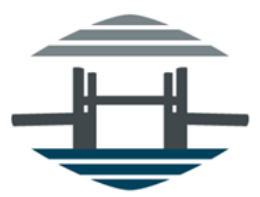

\section{MATERIALS AND METHODS}

\subsection{Cast-in anchor solutions}

Cast-in anchor solutions used to connect large industrial machines to their foundations were tested. Three solutions were investigated: the first one is composed of a coarse M42 threaded rod with a normal series M42 nut fixed with fillet welding; the second one is composed of dimeter $42 \mathrm{~mm}$ bar with a welded square plate $110 \times 110 \times 20 \mathrm{~mm}^{3}$ and a coarse M42 threaded part at one the ends; the last one is composed of two main parts: a steel anchor pocket with $270 \times 270 \times 30 \mathrm{~mm}^{3}$ bottom flange, with an hammer head anchor bolt, which fits the anchor pocket trough a special design. As the main goal of the investigation was the influence of the head size, the cast-in anchor solutions can be identified as relatively "small" head (Fig. 1a), "large" head (Fig. 1b) and "very large" head-size (Fig. 1c). Such a designation is based on the ratio between the bearing pressure and the nominal strength of concrete. Assuming that the applied force to the anchor shaft is rigidly transferred by the anchor head to the surrounding concrete in the bearing zone, the bearing pressure $p_{b}$ can be calculated as it follows:

$$
p_{b}=N_{u, c} / A_{h}
$$

Where, $N_{u, c}$ is given by (1), $A_{h}$ is the effective area of the anchor head.

Table 1 summarizes the characteristics of the investigated anchors. It can be noticed how the Small Head-Size solution is capable to develop very high bearing pressure up to 10 times the related concrete compressive strength, while for the Very Large Head-Size solution the bearing pressure ratio drops under the unity. Steel grade Cl.8.8 was selected for all the anchor solutions to promote concrete cone failure.

Table 1 - Designation of the cast-in anchor solutions

\begin{tabular}{ccccc}
\hline Head-Size & $A_{h}\left(\mathrm{~mm}^{2}\right)$ & $p_{b}\left(\mathrm{~N} / \mathrm{mm}^{2}\right)$ & $p_{b} / f_{c c}(-)$ & Steel grade \\
\hline Small & 1830 & 304 & $4.1^{\text {(a) }}$ & Cl.8.8 \\
Large & 10700 & 52 & 1.7 & Cl.8.8 (shaft)/S275JR (plate) \\
Very Large & 57900 & 10 & 0.3 & Cl.8.8 (bolt)/S275JR (pocket) \\
\hline
\end{tabular}

Notes. (a) for the comparison with the analytical models, the value 4.1 which is calculated on the cubic resistance of the mortar instead of concrete is consider.

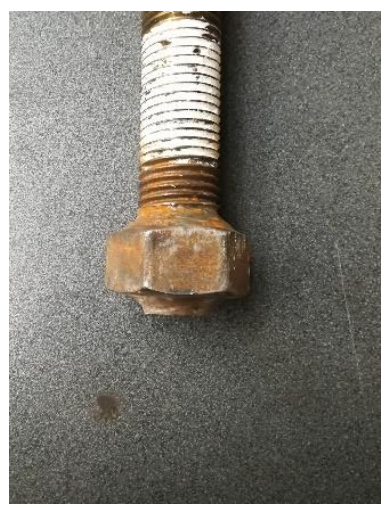

a)

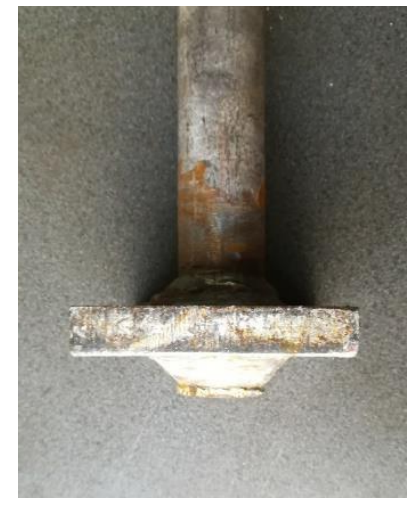

b)

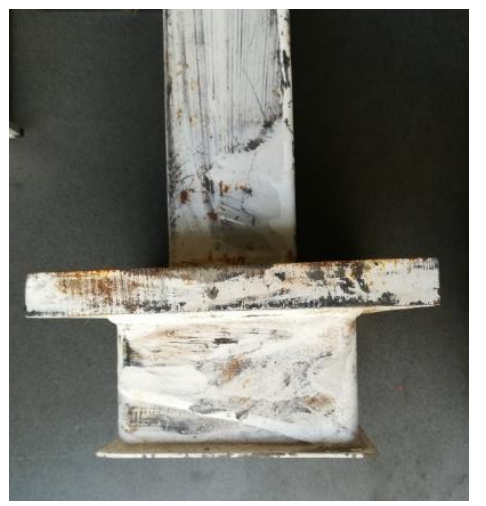

c)

Fig. 1: Details of the investigated cast-in anchor solutions: a) small head-size, b) large head-size, c) very large head-size

\subsection{Reinforced concrete specimens}

A single anchor is installed in the middle of a concrete element (indiscriminately called "slab" in the following) having dimensions of $1250 \mathrm{~mm} \times 1650 \mathrm{~mm}$ in plan and thickness $700 \mathrm{~mm}$. The latter is assumed equal to two times the embedment depth $\left(h_{e f}\right)$, which was $h_{e f}=350 \mathrm{~mm}$ for all the three cast-in anchor solutions. The plan dimensions allow the theoretical development of the concrete cone for the considered $h_{e f}$ assuming $35^{\circ}$ angle [1] [3]. A 


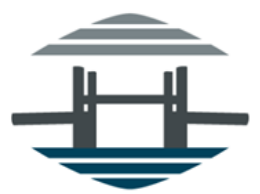

reinforcement mesh grid was designed to prevent bending failure. Considering a simply supported plate, the ultimate load under concentrated load can be written as:

$$
\begin{gathered}
P_{c r}=M_{c r} \cdot 2 \cdot \pi \\
M_{c r}=f_{c t} \cdot W
\end{gathered}
$$

Where: $P_{c r}$ is the concentrate load, which yields to the cracking of the slab, $m_{c r}$ is the cracking bending moment per unit length, $W$ is the section modulus, $f_{c t}$ is the tensile strength of concrete.

To resist the cracking bending moment, a reinforcement mesh grid $200 \times 200 \mathrm{~mm}$ (steel class B450C) has been placed. Specimens were casted with nominal class C20/25 concrete. Three cubes of $150 \mathrm{~mm}$ side were tested for each slab and result of cubic compressive strength $\left(f_{c c, t e s t}\right)$ are reported in Table 3 . For the small head-size only, the anchor is installed using high strength grouting mortar casted inside a corrugated metal pipe after the hardening of the base concrete material. The mortar was cured for minimum seven days before testing and its compressive strength $\left(\mathrm{f}_{\mathrm{cg}, \mathrm{test}}\right)$ was measured on $100 \mathrm{~mm}$ side cubes.

\subsection{Experimental program}

The complete test program is reported in Table 2, and totally, it encompasses nine pullout tests under monotonic load conditions. The experimental tests were carried out at Laboratorio Prove Materiali, Strutture e Costruzioni of Politecnico di Milano (LPMSC). The concrete slab is restrained using a double order reaction frame as shown in Fig. 2. The frame is fixed to the strong floor using tie-down rods. A double action hydraulic jack, with $1000 \mathrm{kN}$ in thrust and $667 \mathrm{kN}$ in pull is used to apply the tensile load to the anchor. The jack is fixed to a rigid frame, which, in turn, is fixed to the strong floor. A spherical pinned connection through a stiff loading plate completed the load transferring system. The applied force is measured using $1000 \mathrm{kN}$ load cell, the vertical displacements are measured using inductive transducers of $100 \mathrm{~mm}$ stroke. The transducers are installed at four different points aligned on two orthogonal diameters passing through the axis of the bolt. The transducers are carefully placed outside the theoretical projection of the concrete cone area. The signals are continuously recorded using an acquisition board connected to a dedicated PC workstation.

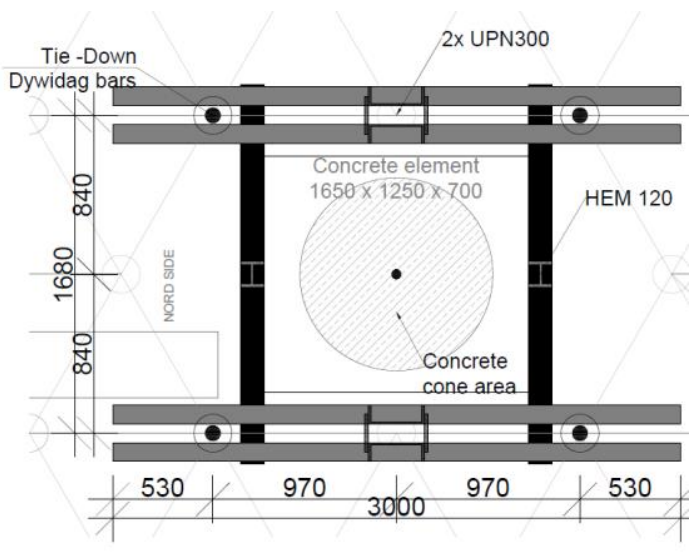

a)

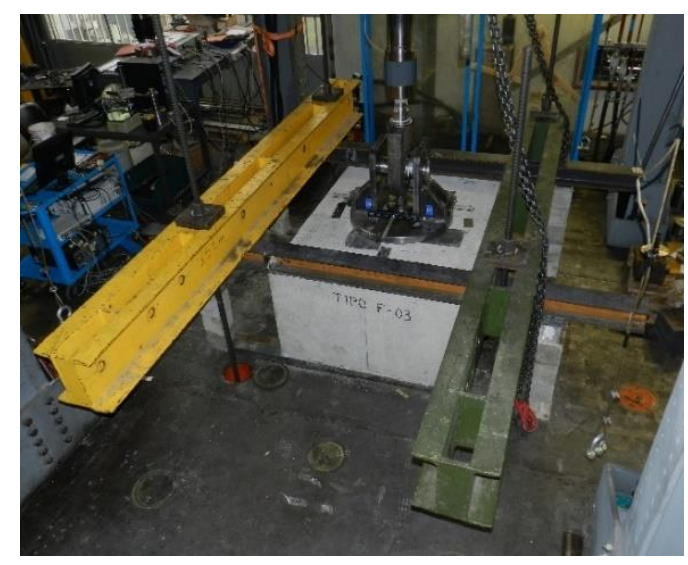

b)

Fig. 2: Test apparatus: a) layout, b) picture

Table 2 - Test program

\begin{tabular}{ccccccc}
\hline Head-Size & $p_{b} / f_{c c}(-)$ & $h_{e f}(\mathrm{~mm})$ & Concrete class & Grouting mortar & Reinforcement & N. of tests \\
\hline Small & 4.1 & 350 & C20/25 & YES & $\phi 10 / 20 \times 20$ & 3 \\
Large & 1.7 & 350 & C20/25 & NO & $\phi 10 / 20 \times 20$ & 3 \\
Very large & 0.3 & 350 & C20/25 & NO & $\phi 10 / 20 \times 20$ & 3 \\
\hline
\end{tabular}




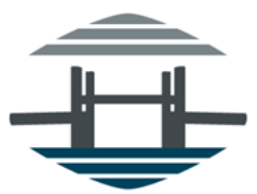

\subsection{Test protocol}

In order to reproduce real site conditions, anchors were lightly preloaded prior testing. All the anchor bolts were preloaded with the same value of the axial force, which was measured by an additional load cell inserted between the loading plate and the washer. After preloading, the specimens were tested applying a monotonic tensile load till the failure mechanism was clearly detected. The system was displacement controlled with a constant rate equal to $0.01 \mathrm{~mm} / \mathrm{s}$, for all the samples.

\section{TEST RESULTS}

The following section reports the results from the experimental campaign with particular emphasis on the effects of different bearing pressures. For all the tested solutions, the load-displacement curve (Fig. 3a, Fig. 4a and Fig. $5 a)$ is characterized by a first branch with high stiffness up a value equal to the applied clamping force. After, it can be noticed an abrupt change in the stiffness with a non-linear branch up to the peak load. As it will be discussed in the next section, the order of magnitude of the displacement at the peak load is comparable for all the solutions, with minor differences mostly related to the local load transfer mechanism. A reduction of the peak load is observed as the bearing pressure increases. Indeed, measured values of the tensile load for the small head-size anchor are lower than values from tests on larger head-sizes.

Tested anchors showed different mechanical response under tensile load considering (i) the load-displacement curves and (ii) the crack pattern at failure. Depending on the developed bearing pressure at anchor's head location, the failure mechanism changes from a local mechanism characterized by concrete cone development to a global mechanism involving the entire concrete slab. Despite the presence of the mortar grouting, the small head-size solution always shows concrete cone breakout mechanism (Fig. 3b). However, it can be clearly noticed the presence of a splitting crack passing through the anchor bolt location, tangential to the corrugated metal pipe. Two different failure mechanisms are detected for the large head-size solution: bending plate failure (Fig. 4b) and concrete cone extraction (Fig. 4c). Fig. 4b shows how the failure mechanism is characterized by the presence of large triangular segments between cracks radially arranged which corresponds to a typical plate failure under bending. Furthermore, a splitting crack develops exactly at the anchor position, which acts like a crack-inducer. Differently from the other cases, very large head-size anchor never forms the cone failure surface. The dominant failure mechanism is the structural collapse of the concrete member under bending (Fig. 5b). However, in one case a flat and asymmetric extraction cone can be recognized (Fig. 5c). Moreover, the peculiar shape of the extraction cone, which slightly differs form literature provisions, is shown in Fig. 6, it starts almost flat in the direction perpendicular to the bending span and it reaches the free edge of the concrete specimen, irrespective of the geometric rules, which should ensures the free concrete cone development. In the other direction (i.e. parallel to the bending span), the cone is steeper (b) than the $35^{\circ}$ degrees from litearture.

Table 3 summarizes the measured load capacities, the strength of concrete at age of testing and the observed failure mode for each test specimen.

Table 3 - Test results

\begin{tabular}{ccccc}
\hline Test code & $\mathrm{N}_{\mathrm{u}, \mathrm{m}, \text { test }}(\mathrm{kN})$ & $\mathrm{f}_{\text {cc,test }}\left(\mathrm{N} / \mathrm{mm}^{2}\right)$ & $\mathrm{f}_{\text {cg,test }}\left(\mathrm{N} / \mathrm{mm}^{2}\right)$ & Failure mode \\
\hline Small head-size $\mathrm{n} .01$ & 455.7 & 32.5 & 48.9 & $\mathrm{CC}$ \\
Small head-size $\mathrm{n} .02$ & 450.7 & 31.6 & 57.9 & $\mathrm{CC}$ \\
Small head-size $\mathrm{n} .03$ & 480.7 & 27.4 & 60.6 & $\mathrm{CC}$ \\
Large head-size $\mathrm{n} .01$ & 509.1 & 30.9 & - & $\mathrm{P} / \mathrm{SP}$ \\
Large head-size $\mathrm{n} .02$ & 548.2 & 32.7 & - & $\mathrm{CC} / \mathrm{SP}$ \\
Large head-size n.03 & 550.1 & 35.5 & - & $\mathrm{CC} / \mathrm{SP}$ \\
Very large head-size n.01 & 618.6 & 32.7 & - & $\mathrm{CC} / \mathrm{SP}$ \\
Very large head-size n.02 & 617.7 & 30.6 & - & $\mathrm{CC} / \mathrm{SP}$ \\
Very large head-size n.03 & 623.9 & 32.7 & - & $\mathrm{CC} / \mathrm{SP}$ \\
\hline \multicolumn{5}{l}{ Where: CC, SP and P indicate Concrete Cone, SPlitting and Plate failure, respectively. }
\end{tabular}




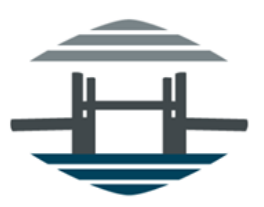

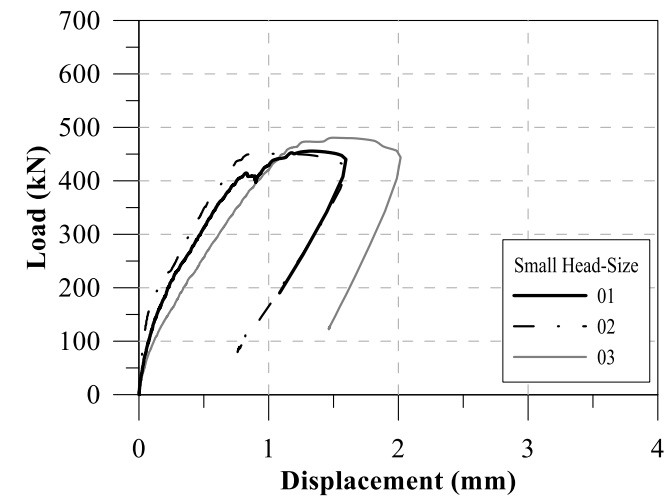

a)

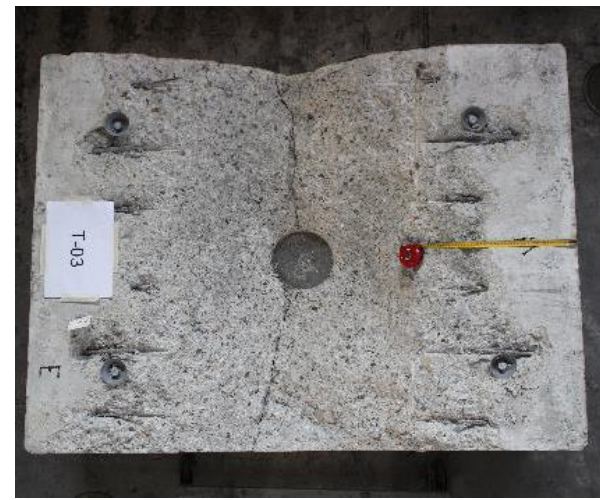

b)

Fig. 3: Small head-size solution: a) Load-displacement curves, b) concrete cone breakout

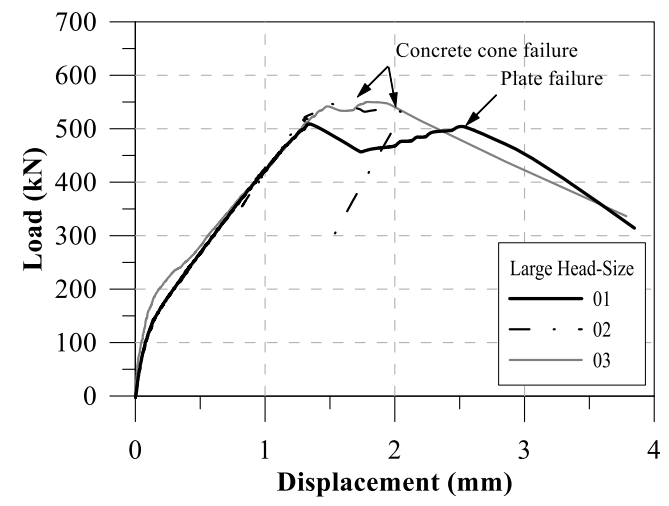

a)

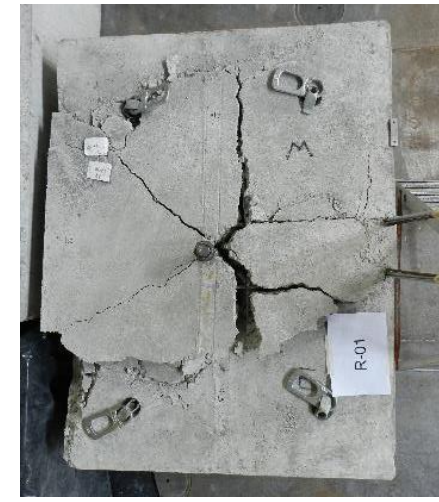

b)

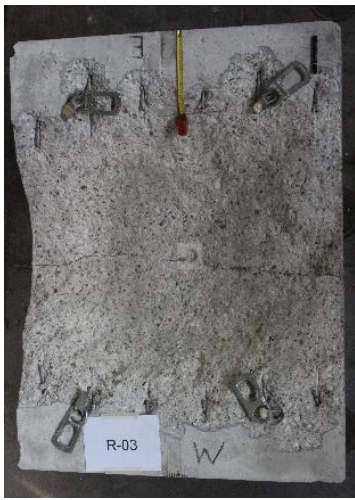

c)

Fig. 4: Large head-size solution: a) Load-displacement curves, b) plate failure, c) concrete cone breakout

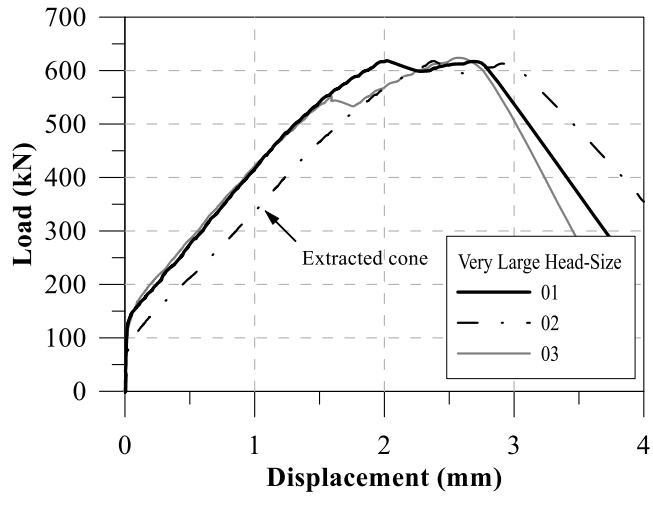

a)

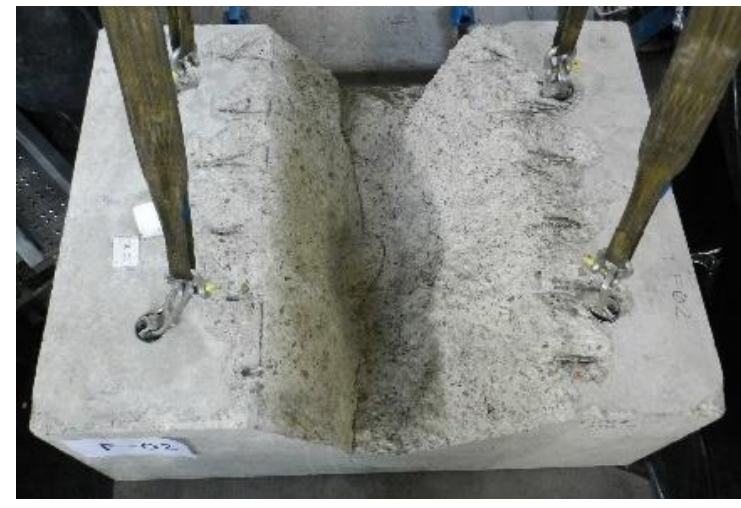

b)

Fig. 5: Very large head-size solution: a) Load-displacement curves, b) typical observed failure mode 

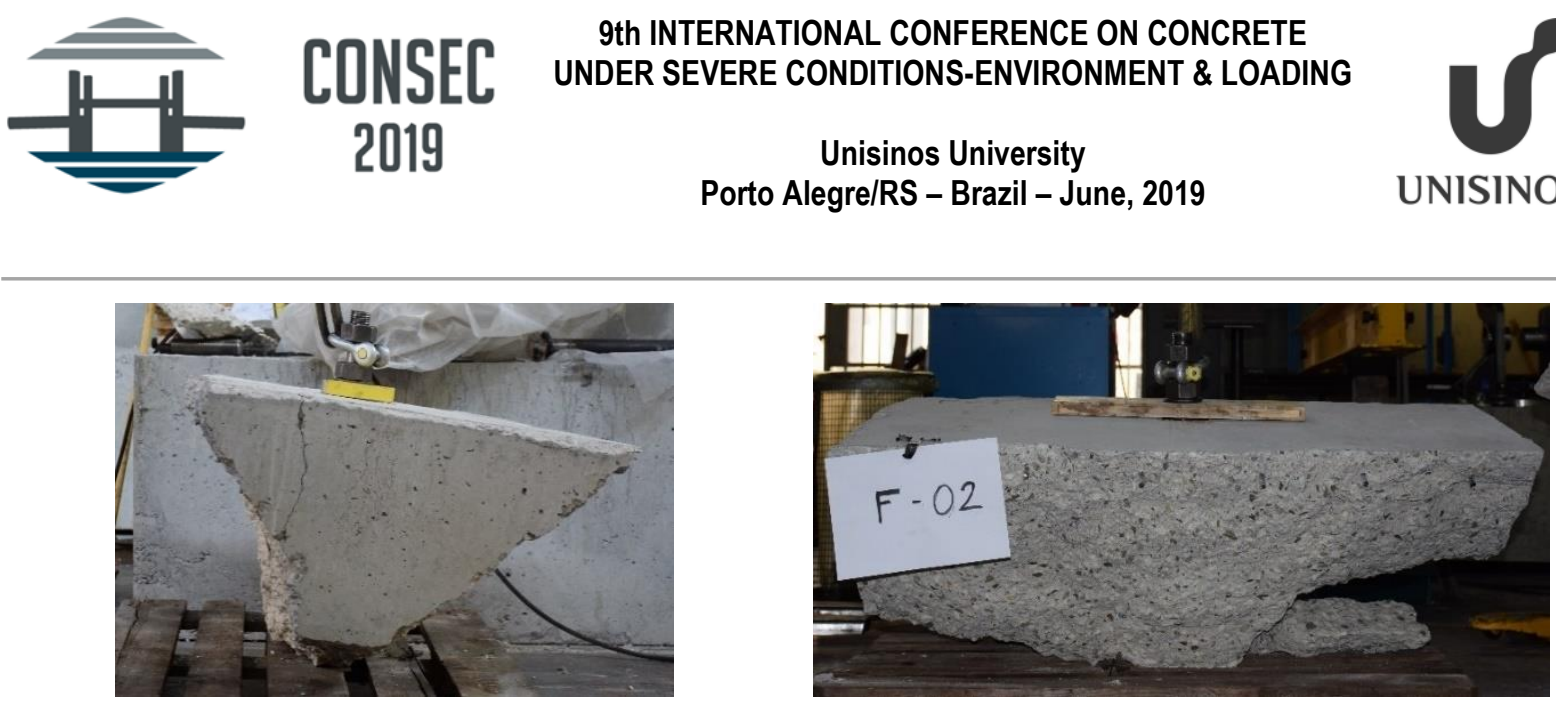

Fig. 6: Flat and asymmetric extraction cone for the very large head-size solution

\section{DISCUSSION OF THE RESULTS}

Results from experimental tests seems to suggest that the direct application of CCD method to large size anchors should be further investigated. Starting from the measured load-displacement curves (Fig. 7), it worth be noticed how the peak load decreases from very large to small head-size solutions. The decreasing in the bearing pressure could lead to a different load transfer mechanism, which migrates from a pure "local" to a "global" member failure, irrespective of the geometric rules fixed to obtain undisturbed conditions during the pullout test, i.e. distances from free edges or supports and minimum thickness of the concrete member equal or greater than 1.5 and 2 times the effective embedment, respectively. A further explanation can be inferred by looking the post-peak branches of the load displacement curves. Considering that at the peak load $40-50 \%$ of the entire cone surface is developed as reported by [9], the abrupt drop of the load occurring for small head-size suggests the complete development of the cone surface. While, a gradual load reduction is evident for the large head size. This could be the evidence of a load transfer mechanism involving the bending behavior of the slab activating also the steel reinforcement.

Furthermore, the ratio between the measurement from the additional load cell and the applied tensile force is calculated and different values of relative stiffness are obtained. Specifically, the relative stiffness ratio for the first branch of the load-displacement curves can be calculated as the following:

$$
k=\frac{k_{s}}{k_{c}}=\frac{\left(E_{s} \cdot A_{s}\right) / L_{s}}{\left(E_{c} \cdot A_{c}\right) / L_{c}} \cong \frac{N_{s}}{F_{\text {ext }}}
$$

Where: $k_{s}$ is the axial stiffness of the anchor bolt, $E_{s}$ is the Young's modulus of steel, $A_{s}$ is the cross section area of the anchor bolt, $L_{s}$ is the length of the anchor bolt, $k_{c}$ is the axial stiffness of the volume of concrete involved in the mechanism, $E_{c}$ is the Young's modulus of concrete, $A_{c}$ is the cross section area of the concrete involved in the mechanism, $L_{c}$ is the depth of concrete involved in the mechanism, $N_{S}$ is the load from the additional load cell and $F_{\text {ext }}$ is the applied external tensile force.

Average values of relative stiffness are summarized in Table 4. They suggest that the volume of concrete involved in the failure mechanism could be directly related to the head-size of the anchor and, hence, to the bearing pressure. Therefore, high bearing pressure could lead to a diffusive mechanism in the concrete member in which an hydrostatic stress filed is developed in the bearing zone and severe crushing of material might occur [10]. Conversely, as the contact pressure diminishes, concrete is preserved from crushing and the load transfer could involve the entire concrete slab prevalently in bending behavior.

The vertical displacements measured for the small head-size solution (at the peak load) are four times lower than the displacements for the other solutions. However, this could be related to the specific technology of the anchoring solution. In fact, the anchor bolt is installed in high strength mortar, hence the bond between the anchor bolt shaft and the mortar, and between the corrugated metal pipe and concrete, could represent non-negligible contributions to the to the axial stiffness of the anchoring system. 

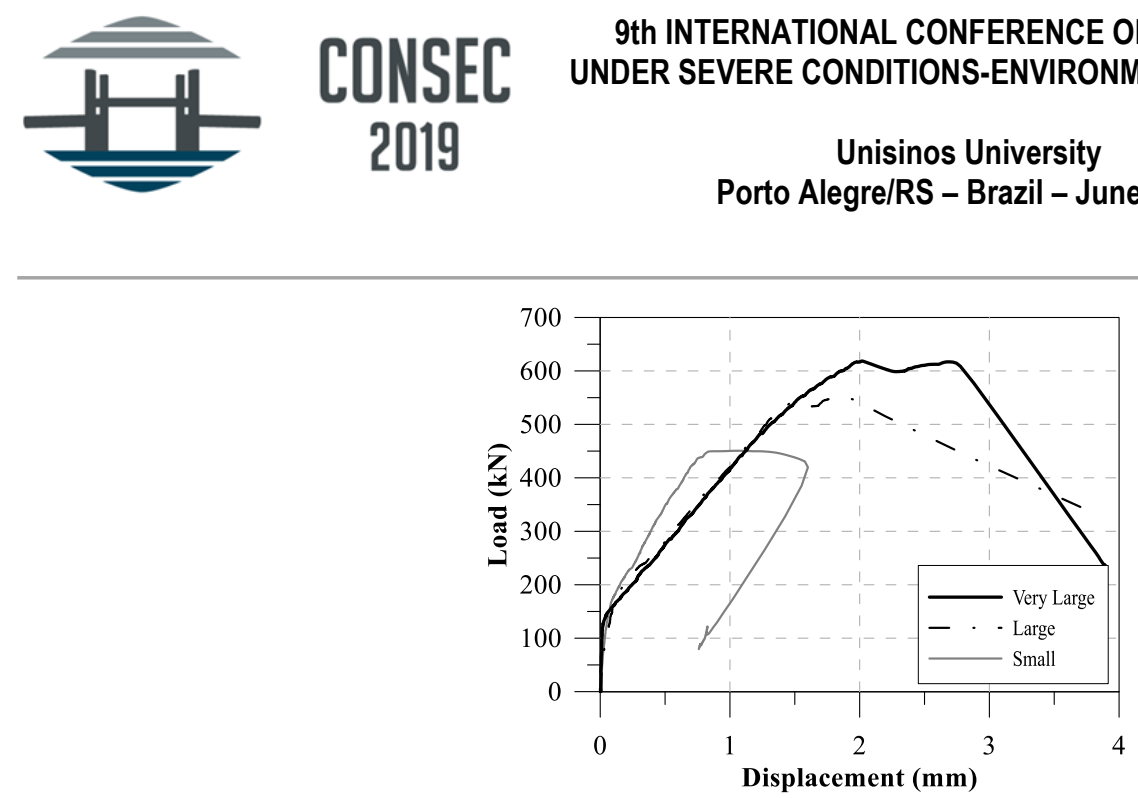

Fig. 7: Comparison between experimental load-displacement curves

Results from experimental tests can be compared in terms of normalized load capacities calculated as follow:

$$
N_{u, c}=N_{u, c, t e s t} \cdot\left(\frac{f_{c c, t e s t}}{f_{c c, n o m}}\right)^{0.5}
$$

Where: $N_{u, c}$ is the normalized capacity, $N_{u, c, t e s t}$ is the load capacity from the experimental test, $f_{c c, t e s t}$ is the concrete compressive strength measured on cubes at the age of testing and is the nominal concrete strength, which is fixed equal to $30 \mathrm{~N} / \mathrm{mm}^{2}$.

Calculating the ratio between the measured and the predicted load capacities (Table 4 and Fig. 8), it follows how the increasing of the head-size leads to higher capacities. Neverthless, such a increasing is lower than the previsions from other refinement proposals of CCD method. In particular, the factor $\psi_{A H}$ calculated according to [8] are reported for the different type of anchors. The authors question the applicability of the correction factor for CCD mererly taking into account the head-size. Boundary conditions different from ring confinement need to be considered in the formulation of the correction factor.

The CCD method could be successfully applied to the small head-size solution. However, the load-bearing capacity in that case seems to be overestimated due to the specific technology of the solution. In particular, as shown in Fig. 9a, the shape of the extraction is not regular and it can be noticed how a first inclined crack propagates till the corrugated metal pipe, hence a slip between the pipe and the concrete is clearly detected with a subsequent geometrical discontinuity in the main macro-crack. On this basis, calculating again the capacity, taking as effective embedment depth the distance from the beginning of the crack in the concrete part and the free surface of the specimen, the experimental results matches the prediction from CCD method.

As demonstrated also in other research work [10], the reduction in the bearing pressure preserves concrete from local crushing. For the large head size solution this could have led to the specific plate bending failure mechanism, in which large triangular portions with approximately $35^{\circ}$ degrees of inclination are radially arranged between radial cracks (Fig. 9b). At anchor's head level, a cone shaped portion of $7 \mathrm{~cm}$ depth is created (Fig. 9c) in which an hydrostatic stress field could develop and no crushing is obtained due to the limited value of bearing pressure. However, this zone is quite limited with respect the entire concrete cone surface and not even recognizable in the case of "Very large" head size anchors. Nevertheless, the discussion cannot involve the case of small head size anchor since a higher level of bearing resistance can be obtained and local crushing might have been prevented. 

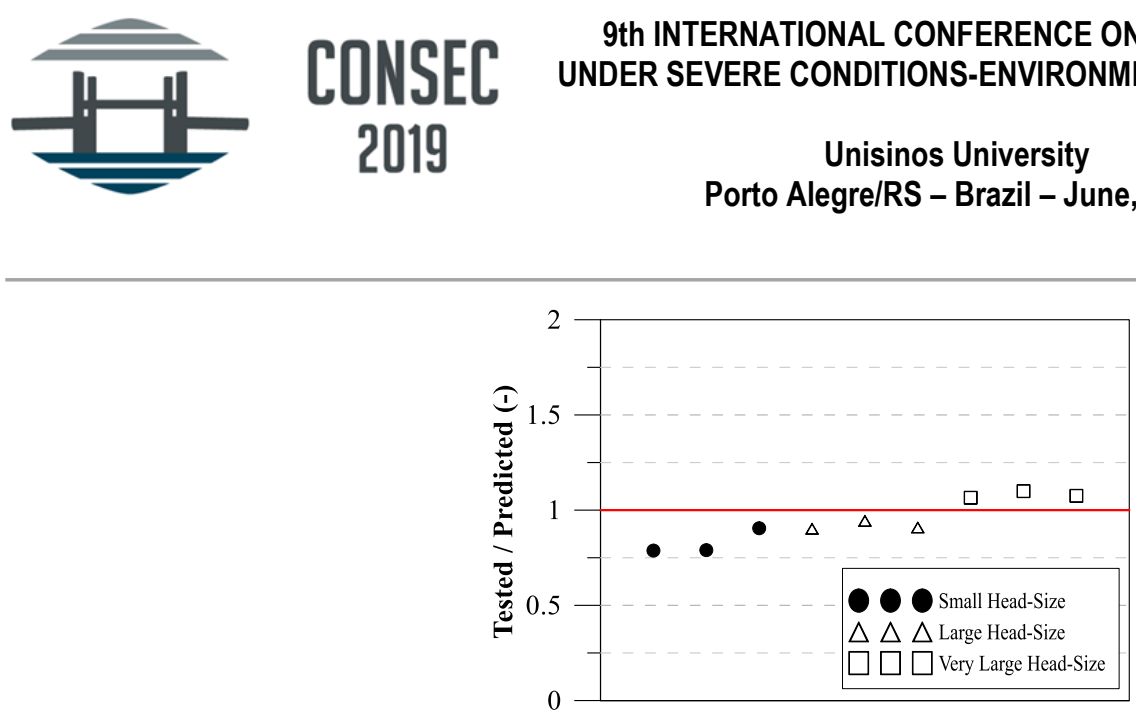

Fig. 8: Tested/Predicted values for all the experimental tests

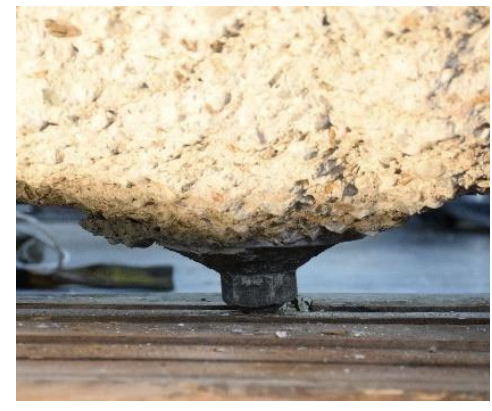

a)

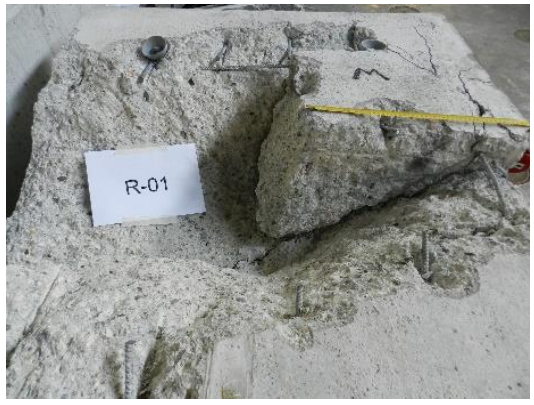

b)

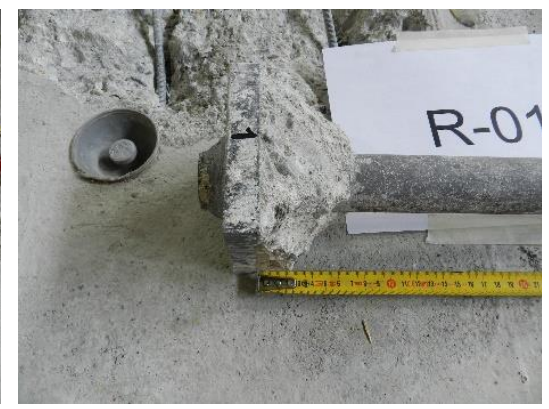

c)

Fig. 9: Extraction cones for: a) the small head and b) for the large head-size solutions, c) detail of cone shape portion at the anchor's head

Table 4 - Discussion of the test results

\begin{tabular}{cccccccccc}
\hline Head-Size & $\mathrm{N}_{\mathrm{u}, \mathrm{m}, \text { test }}(\mathrm{kN})$ & $\mathrm{f}_{\mathrm{cc}, \text { test }}\left(\mathrm{N} / \mathrm{mm}^{2}\right)$ & $\mathrm{f}_{\mathrm{cg}, \text { test }}\left(\mathrm{N} / \mathrm{mm}^{2}\right)$ & $\mathrm{N}_{\mathrm{u}, \mathrm{m}}(\mathrm{kN})$ & $\mathrm{R}^{(\mathrm{a})}$ & $\psi_{A H}{ }^{(\mathrm{b})}$ & $\sigma(\mathrm{kN})$ & $\mathrm{CV}(\%)$ & $\mathrm{k}(-)$ \\
\hline Small & 462.3 & $27.4 \div 32.5$ & $48.9 \div 60.6$ & 459.9 & 0.83 & - & 37.3 & 8.1 & 0.16 \\
Large & 535.8 & $30.9 \div 35.5$ & - & 510.7 & 0.92 & 1.24 & 12.4 & 2.4 & 0.18 \\
Very Large & 620.1 & $30.6 \div 32.7$ & - & 600.4 & 1.08 & 1.47 & 9.8 & 1.6 & 0.05
\end{tabular}

Note. (a) $\mathrm{R}=$ Tested / predicted; (b) Modification factor for head size according to Nilforoush [8]

\section{CONCLUSIONS}

Three different cast-in anchors were tested under monotonic tensile force mainly focusing on the influence of the bearing pressure on the (i) anchor response and (ii) the mode of failure. As a relevant test parameter, the bearing pressure ratio $\left(p_{b} / f_{c c}\right)$ has been considered varying the head size while the embedment depth was kept constant. The following conclusions can be drawn:

1. An increasing of $8 \%$ in the load bearing capacity calculated with CCD method is recognized only in the case of very large head size $\left(p_{b} / f_{c c}<1\right)$, while for the remaining cases of $p_{b} / f_{c c}=1.7$ and 4.1 the ratio between tested and predicted values are 0.92 and 0.83 , respectively. No match is obtained considering the modification factor for the head size according to the literature proposals.

2. A particular arrangement of the bearing zone has been investigated for the small head-size anchor, namely the anchor head is surrounded by high strength grouting mortar casted inside a corrugated metal pipe. This condition is favorable with respect to plain concrete since the crushing phenomenon, which is mainly responsible for anchor displacement, is prevented.

3. Depending on the bearing pressure ratio, a migration from local mode of failure (i.e. concrete cone) to global mode of failure involving the entire concrete slab is observed as far as the final crack pattern is considered. Aside the occurrence of a splitting crack in all tests for which surface reinforcement has been placed on purpose, a fully developed concrete cone surface with $35^{\circ}$ angle characterizes the small head-size. While, in 


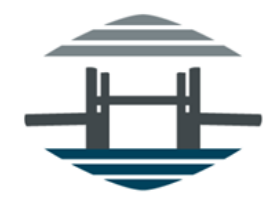

the case of large head size steeper cone surfaces and wider splitting cracks are observed. Moreover, a clear plate failure characterized by radially spaced cracks starting from the point of the load application (i.e. anchor) is observed.

4. A further explanation for the previous point can be sustained considering the load-displacement behavior for the different type of anchors. In small head size an abrupt drop of the load occurs after reaching the peak, as expected in a pure concrete cone surface development. While, in the case of large head size, post peak branch is characterized by a gradual load reduction. This result suggests that after the partial development of the cone surface (i.e. 40-50\%), for which the peak load is reached, the load transfer involves the global bending behavior of the concrete slab activating also the steel reinforcement.

\section{ACKNOWLEDGEMENTS}

This research work was carried out with the financial support of Danieli \& C. Officine Meccaniche S.p.A., Italy. Mr. Alberto Garbari is warmly thanked for authorizing the use of experimental data. The authors would also like to thank all the members of the technical staff of LPMSC, room GIMED.

\section{REFERENCES}

[1] R. Eligehausen, R. Mallèe, and J. Silva, Anchorage In Concrete Construction. Berlin: Ernst \& Sohn, 2006.

[2] J. Ožbolt, R. Eligehausen, and H.-W. Reinhardt, "Size effect on the concrete cone pull-out load," Int. J. Fract., vol. 95, pp. 391-404, 1999.

[3] W. Fuchs, R. Eligehausen, and J. E. Breen, "Concrete Capacity Design (CCD) Approach for Fastening to Concrete," ACI Struct. J., vol. 92, p. 23, 1995.

[4] CEN/TC250, "EN1992-4 - Eurocode 2: Design of concrete structures - Part 4: Design of fastenings for use in concrete," 2018.

[5] ACI Committee 318, Aci 318-14. 2014.

[6] N. H. Lee, K. S. Kim, C. J. Bang, and K. R. Park, "Tensile-headed anchors with large diameter and deep embedment in concrete," ACI Struct. J., vol. 104, no. 4, pp. 479-486, 2007.

[7] J. Ožbolt, R. Eligehausen, G. Periškić, and U. Mayer, "3D FE analysis of anchor bolts with large embedment depths," Eng. Fract. Mech., vol. 74, no. 1-2, pp. 168-178, 2007.

[8] R. Nilforoush, "Anchorage in Concrete Strucutres - Numerical and experimental Evaluation of LoadCarrying capacity of CI headed anchors and PI adhesive anchors," Luleå University of Technology, 2017.

[9] R. Eligehausen and G. Sawade, "A fracture mechanics based description of the pull-out behavior of headed studs embedded in concrete," Fract. Mech. Concr. Struct., pp. 281-299, 1989.

[10] G. Di Nunzio, A. Marchisella, and G. Muciaccia, "Influence of head-size on concrete cone capacity: a comparison for two cast-in solutions," in 12th fib International PhD Symposium in Civil Engineering, 2018, pp. 1-8. 